University of Nebraska - Lincoln

DigitalCommons@University of Nebraska - Lincoln

Industrial and Management Systems

Industrial and Management Systems

Engineering Faculty Publications

Engineering

1994

\title{
Ascertaining Important Features for Industrial Simulation Environments
}

Gerald Mackulak

Arizona State University at the Tempe Campus

Jeffery Cichran

Paul Savory

University of Nebraska at Lincoln, psavory2@gmail.com

Follow this and additional works at: https://digitalcommons.unl.edu/imsefacpub

Part of the Industrial Engineering Commons, Operational Research Commons, and the Other Operations Research, Systems Engineering and Industrial Engineering Commons

Mackulak, Gerald; Cichran, Jeffery; and Savory, Paul, "Ascertaining Important Features for Industrial Simulation Environments" (1994). Industrial and Management Systems Engineering Faculty Publications. 53.

https://digitalcommons.unl.edu/imsefacpub/53

This Article is brought to you for free and open access by the Industrial and Management Systems Engineering at DigitalCommons@University of Nebraska - Lincoln. It has been accepted for inclusion in Industrial and Management Systems Engineering Faculty Publications by an authorized administrator of DigitalCommons@University of Nebraska - Lincoln. 


\title{
Ascertaining Important Features For Industrial Simulation Environments
}

\author{
Gerald T. Mackulak, Paul A. Savory, and Jeffery K. Cochran \\ Systems Simulation Laboratory \\ Department of Industrial and Management Systems Engineering \\ Arizona State University \\ Tempe, Arizona 85287-5906
}

\begin{abstract}
Recent years have witnessed the development and commercial release of multiple simulation tools, environments, and intelligent simulators. Each release seems to contain additional advanced features designed to simplify simulation use and increase the productivity of model builders. But to date, no one has addressed feature definition from the viewpoint of a simulation practitioner. This paper discusses our efforts to identify and prioritize simulation features deemed most desirable from the practitioner viewpoint. A series of three questionnaires were developed and administered to a group of qualified simulation practitioners. With results that are of interest to simulation users, researchers, and simulation software developers, the survey responses reveal not only what practitioners feel are the most important features of presently available commercial packages, but also identify important areas for future development.
\end{abstract}

\section{Keywords}

simulation features, integrated environments, simulators, knowledge-based simulation 


\subsection{Introduction}

The many uses of simulation range from comparing alternative systems to answering capacity and feasibility questions. Unfortunately, the potential benefits that discrete-event simulation offers are impeded by the high level of expertise necessary to successfully conduct a sound simulation study. As a solution, the availability of simulation tools has greatly increased in recent years [see bibliographical items 1 through 9 for a sampling of current commercial and research efforts].

Conceptualizing the next generation of simulation software tools required to solve manufacturing problems is a difficult task. Since 1987, the research efforts of the Systems Simulation Laboratory (SSL) have resulted in the development and release of three manufacturing-based simulation environments [10, 11, 12, 13, 14, 15]. During the development of our latest prototype, IntelliSIM (Intelligent Simulation), we were continually challenged to validate our perception of the important features and technologies required in an intelligent, manufacturing-based simulation environment.

Several authors [16, 17, 18, 19, 20, 21] have proposed differing lists of important simulation features. Unfortunately, no research or commercial manufacturing-based simulation environment includes all of them. Is this a result of cost considerations, implementation difficulties, or perceived modeler needs? As a means of addressing this question, we decided it would be prudent to evaluate the views of simulation practitioners on what features they require in an industrial simulation environment. To accomplish this, the SSL developed and administered three surveys [22]. The objective of the second of these surveys was to explore the importance of specific simulation environment features. The results of this survey are the subject of this paper.

The paper is divided into five sections. Section 2.0 describes the survey development process and introduces the survey participants. Section 3.0 reviews the survey contents and categories. Section 4.0 presents the survey responses on the importance of simulation environment features. The paper concludes by listing the top ten simulation features identified by the participants. 


\subsection{The Survey Process}

To assess simulation practitioners views on industrial simulation environment features, we were extremely concerned with obtaining biased responses from individuals with little practical simulation experience. To alleviate this fear, we developed and administered a total of three surveys [22]. Such an approach allowed us to evaluate respondents qualifications and selectively restrict participation to appropriately qualified individuals. Rigorous group discussion and a review of similar surveys resulted in our using the following hierarchy of three surveys (Figure 1):

- Level 1: How is simulation used?

- Level 2: What features do practitioners require in a simulation environment?

- Level 3: How well does the IntelliSIM environment meet a user's needs?

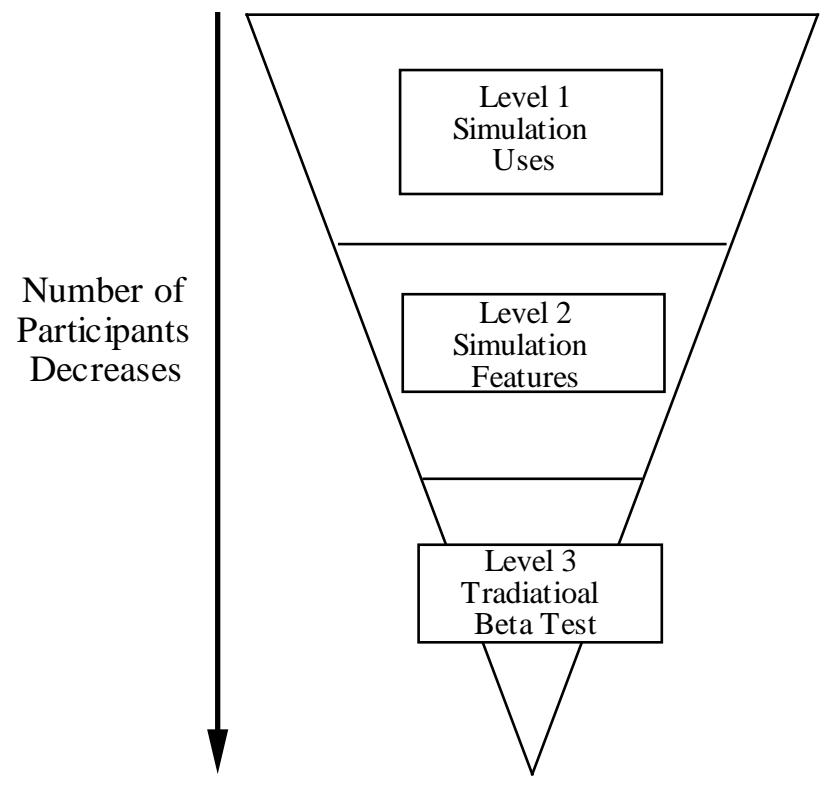

Figure 1. Hierarchy of Simulation Surveys.

Thus, rather than having a single, long survey, we use a series of shorter surveys. In addition to the advantage of having an improved response rate due to the reduced time to complete a survey, this approach also allowed us to carefully screen the survey participants at each stage or level of the survey hierarchy. This screening permitted us to the narrow the scope 
and wording of each survey to its respective target audience and to obtain responses from qualified individuals.

The objective of the first survey in the hierarchy, Level 1, was to explore current simulation practices, ideas, and concepts. To collect these simulation project characteristics, we sought a broad mixture of responses. The Level 1 survey was sent electronically or by mail to over 500 simulation practitioners, research fellows in industry and research institutes, simulation consulting organizations, and other simulation funding agencies, all over the world.

A total of 138 Level 1 survey responses were received. Table 1 is a sampling of industrial participant organizations that responded. In addition, responses were received from simulation practitioners from nine foreign countries (Austria, Canada, India, Japan, Korea, Mexico, Netherlands, Singapore, Taiwan).

\begin{tabular}{|c|c|}
\hline Aerospace Corporation & Inland Flat Products \\
\hline AFIT/ENS & Kawasaki Steel Corporation \\
\hline AMC/XPYR & M\&E Pacific \\
\hline American Airlines & McDonnell Douglas \\
\hline Arizona Department of Transportation & Mead Data Central \\
\hline Automation Associates & OAS/XRC \\
\hline Battelle Pacific NW Laboratory & Port Authority of New York \\
\hline Boeing Commercial Airplane Group & Pritsker Corporation \\
\hline Boeing Defense & Regenerative Institute \\
\hline CACI & Rocketdyne \\
\hline CESIMO & Rockwell International \\
\hline Cypress Semiconductors & Rust International \\
\hline Digital Equipment Corporation & Shizuoka-Ken \\
\hline EXTECH & Sky Chefs \\
\hline General Dynamics & United States Postal Service \\
\hline Hughes & Xerox \\
\hline IBM &
\end{tabular}

Table 1. Industrial organizations participating in the Level 1 survey.

The purpose of the Level 2 survey was to identify the important manufacturing-based simulation environment features that simulation practitioners require. Unfortunately, the level of experience and expertise required to competently comment on a feature's value drastically restricts the potential respondent base. From the Level 1 survey respondents, a subset of 
manufacturing simulation practitioners was selected to participate in the Level 2 survey. We sought responses only from simulation practitioners who have experience in modeling real manufacturing systems (as opposed to classroom studies or research). In fact, we used the qualifying phrase, "Have you conducted a simulation study for money?" as a subset discriminator. This selection criteria reduced the Level 1 respondent list to a set of 65 qualified individuals. All 65 were requested to participate in the Level 2 survey and a total of 29 responses were returned. Even though the sample size is small, these responses do come from four different countries and a range of industrial environments. Respondents classify their production environment as education/research (33\%), project/custom products (17\%), mass production/high volume (14\%), batch production/medium volume (9\%), job shop/high mix (7\%), continuous flow/high volume (5\%), and other (15\%). In addition, respondents indicated that their primary use of simulation is for design (27\%), research (22\%), planning (20\%), scheduling (13\%), assignments/allocation (12\%), and other (6\%).

As the hierarchy in Figure 1 indicates, participants for the Level 3 survey were selected from the Level 2 respondents. The Level 3 participants performed an in-depth, beta test of the IntelliSIM environment. Results of that beta test are available to CAM-I/IMAR member company participants in Volume II of the IntelliSIM final project report and are also currently being evaluated for possible publication.

The methodology for developing the surveys involved a series of iterations (Figure 2). Each iteration was designed to refine the categories and the interest areas, so as to assure unbiased question wordings. Survey literature was referenced to assure the accuracy and validity of the survey instrument. The development of the individual questions and selection of question scale ranges was done to assure no bias toward any particular simulation feature. A pre-test was conducted by administering the survey to over 50 graduate students in advanced simulation classes at Arizona State University. Responses and comments from the students were used to evaluate and modify the survey design. A statistical analysis of the student responses was used to finalize development. 
To ease the data analysis, survey responses were stored in a database created with the PARADOX (Borland International) database software. The capabilities of PARADOX are quite extensive and include features such as basic statistics, feature matching, quick search and retrieval, and entry grouping.

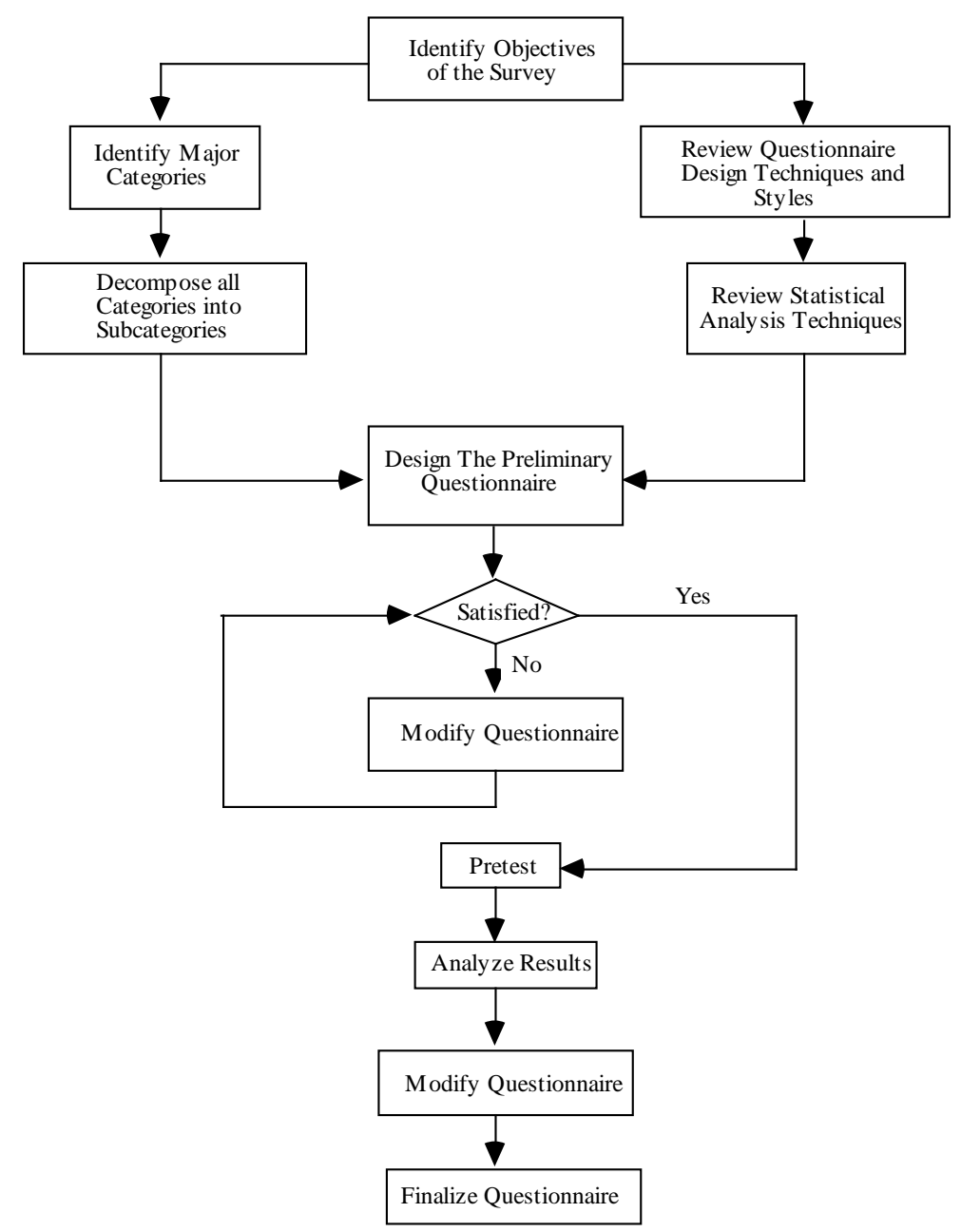

Figure 2. Questionnaire development process.

\subsection{The Level 2 Survey}

The Level 2 survey requested that respondents rate the individual importance of simulation features from a list of over fifty potential features complied from the literature $[16,17$, 18, 19, 20, 21] and commercially available simulation packages. To ease understanding, the list was divided into categories (or steps). The most logical set of categories that related to our target audience were the general steps necessary to conduct a sound simulation study (Table 2). The 
exception to this categorization is the category "General Features". The General Features category contains the qualitative features of a simulation tool that exist throughout the tool and do not correspond to any specific simulation step.
General Features
Data Acquisition And Analysis Features
Model Development Features
Validation And Verification Features
Model Execution Features
Output Analysis Features
Documentation Features
Simulation Project Data Features
Methods Of User Interface Features

Table 2. Categories of simulation environment features.

The Level 2 survey is 6 pages long and consists of 83 questions. It operates in two stages. The first 62 questions present 54 unique simulation environment features and require the survey participant to rate a feature's importance as either Very Important, Important, Less Important, or Not Important. The remaining 21 questions of the survey measure how our prototype research environment, IntelliSIM, compares to a participants needs and expectations. To accomplish this, survey participants were provided with a computer diskette containing a tutorial demonstration of the IntelliSIM simulation environment. After viewing the tutorial, participants were asked to answer specific questions regarding IntelliSIM’s implementation of various features.

\subsection{Presentation of Results}

Our objective in presenting the Level 2 survey results is to highlight simulation environment features that simulation practitioners view as important. Because of the small sample size, complex statistical conclusions are meaningless. However, the high level of real- 
world modeling experience required of participants guarantee that the responses do offer insight into areas for future research and/or commercial product development. 
G.T. Mackulak, P. Savory, and J.K. Cochran (1994), “Ascertaining Important Features for Industrial Simulation Environments," Simulation, Volume 63, No. 4, pp. 211-221.

Table 3. Ranked survey results of simulation environment features. 
Table 3 presents a ranked summary of the survey results. The first column indicates the simulation environment feature and the second presents the average response of a feature, which ranges from a minimum of 1 to a maximum of 4 . The third column displays the coefficient of variation (response standard deviation divided by its mean) among the responses. The final column ranks all 54 potential features on the basis of weighted average response. The ranking is from 1 to 54, where 1 is the feature with the highest weighted average response and 54 is the lowest weighted average response. A tie breaking rule of lowest coefficient of variation first was used in cases where the average weighted response values were equal.

The remainder of this section presents detailed results for each of the simulation categories listed previously in Table 2. The table for each category follows a similar format. The first column indicates the simulation environment feature and the second presents the average weighted participant response. Individual features within a category’s table are listed according to their average responses, with the highest being first and the lowest listed last. The middle columns, VI (Very Important), I (Important), LI (Less Important), and NI (Not Important), present the distribution of participant responses among these classifications. The fifth column, average, computes a weighted average of the survey responses, where the weightings are VI $=4, \mathrm{I}=3$, LI $=2$, and NI $=1$. The final column displays the coefficient of variation among the responses.

\section{Category: General Features}

\begin{tabular}{|l|r|r|r|r|r|l|}
\hline \multicolumn{1}{|c|}{ Feature } & \multicolumn{1}{c|}{ VI } & \multicolumn{1}{c|}{ I } & \multicolumn{1}{c|}{ LI } & \multicolumn{1}{c|}{ NI } & \multicolumn{1}{c|}{ Average } & CV \\
\hline Friendly interface & $79.3 \%$ & $20.7 \%$ & $0 \%$ & $0 \%$ & 3.79 & 0.11 \\
\hline Generous graphics & $62.1 \%$ & $31.0 \%$ & $6.9 \%$ & $0 \%$ & 3.55 & 0.18 \\
\hline Windows and menus & $44.8 \%$ & $48.3 \%$ & $6.9 \%$ & $0 \%$ & 3.38 & 0.18 \\
\hline On-line help & $41.4 \%$ & $44.8 \%$ & $13.8 \%$ & $0 \%$ & 3.28 & 0.21 \\
\hline Multiple platforms & $55.2 \%$ & $24.1 \%$ & $13.8 \%$ & $6.9 \%$ & 3.28 & 0.29 \\
\hline Tutorial & $35.7 \%$ & $42.9 \%$ & $21.4 \%$ & $0 \%$ & 3.14 & 0.24 \\
\hline Word processor or spreadsheet & $17.2 \%$ & $51.7 \%$ & $27.6 \%$ & $6.9 \%$ & 2.83 & 0.35 \\
\hline
\end{tabular}

Table 4. Importance of general simulation features. 
The highest rated feature, according to the survey, is a consistent and friendly user interface (Table 4). A strong graphic capability to present input, output, and run-time statistics is also highly rated. Other important features include the ability to access the environment through menus and graphical windows, on-line help, and a tutorial/training module to quickly acquaint the user with the environment. Features of lesser importance include the need for the environment to operate on

different computer hardware platforms and the ability to interface with a word processor or spreadsheet for report generation.

\section{Category: Data Acquisition and Analysis}

\begin{tabular}{|l|c|c|c|c|c|c|}
\hline \multicolumn{1}{|c|}{ Feature } & VI & I & LI & NI & Average & CV \\
\hline Distribution fitting & $62.1 \%$ & $27.6 \%$ & $3.4 \%$ & $6.9 \%$ & 3.45 & 0.25 \\
\hline Automatic data collection & $24.1 \%$ & $41.4 \%$ & $24.1 \%$ & $10.3 \%$ & 2.79 & 0.34 \\
\hline
\end{tabular}

Table 5. Importance of input data acquisition and analysis features.

Respondents indicate (Table 5) that the fitting of input data to probability distributions and parameter estimation is very important. There is little demand for a simulation tool that performs in data collection. If you examine the earlier percentages of simulation usage you get an indication as to why automatic data collection seems of lesser importance, in that only a small percentage use simulation for shop floor control issues.

\section{Category: Model Development}

\begin{tabular}{|l|c|c|c|c|c|c|}
\hline \multicolumn{1}{|c|}{ Feature } & VI & I & LI & NI & Average & CV \\
\hline Library of reusable modules & $58.6 \%$ & $37.9 \%$ & $3.4 \%$ & $0 \%$ & 3.55 & 0.16 \\
\hline Automated model abstraction & $41.4 \%$ & $44.8 \%$ & $13.8 \%$ & $0 \%$ & 3.28 & 0.21 \\
\hline Pre-existing models to modify & $31.0 \%$ & $51.7 \%$ & $13.8 \%$ & $3.4 \%$ & 3.10 & 0.25 \\
\hline No user coding & $31.0 \%$ & $51.7 \%$ & $10.3 \%$ & $6.9 \%$ & 3.07 & 0.27 \\
\hline Graphical model building & $17.2 \%$ & $48.3 \%$ & $31.0 \%$ & $3.4 \%$ & 2.79 & 0.28 \\
\hline Access to simulation code & $21.4 \%$ & $32.1 \%$ & $39.3 \%$ & $7.1 \%$ & 2.68 & 0.34 \\
\hline
\end{tabular}


Table 6. Importance of model development features.

The ninth ranked feature, according to the survey, is a library of re-usable modules of simulation code (Table 6). An automated model abstraction tool to develop and view models at different levels of detail is also viewed as useful. Features that arouse less interest include the ability to develop models without any user coding, graphical (iconic) model building, and access to the simulation code.

\section{Category: Validation and Verification}

\begin{tabular}{|l|r|r|r|r|r|l|}
\hline \multicolumn{1}{|c|}{ Feature } & \multicolumn{1}{c|}{ VI } & \multicolumn{1}{c|}{ I } & \multicolumn{1}{c|}{ LI } & \multicolumn{1}{c|}{ NI } & Average & CV \\
\hline Interactive debugger & $69.0 \%$ & $31.0 \%$ & $0 \%$ & $0 \%$ & 3.69 & 0.13 \\
\hline Model validation test & $69.0 \%$ & $17.2 \%$ & $13.8 \%$ & $0 \%$ & 3.55 & 0.21 \\
\hline Completeness checker & $51.7 \%$ & $37.9 \%$ & $6.9 \%$ & $3.4 \%$ & 3.38 & 0.23 \\
\hline Model pre-analyzer & $41.4 \%$ & $37.9 \%$ & $17.2 \%$ & $3.4 \%$ & 3.17 & 0.27 \\
\hline
\end{tabular}

Table 7. Importance of model validation and verification features.

Participants indicate (Table 7) a strong interest in any tool assisting in validation and verification. A majority of participants view an interactive debugger for error checking and code tracing as one of the essential tools for simulation. There is also a great demand for a tool that aids validation by testing to make sure that the model adequately represents the real-world system. Participants also express interest in a completeness checker that tests to determine if all necessary simulation data is specified before execution of the model. In addition, participants identify the need for a model pre-analyzer to identify logical errors in the model (e.g., existence of severe bottlenecks). 


\section{Category: Model Execution}

\begin{tabular}{|l|c|r|r|r|r|c|}
\hline \multicolumn{1}{|c|}{ Feature } & VI & I & LI & NI & Average & CV \\
\hline Interrupt and resume execution & $58.6 \%$ & $27.6 \%$ & $10.3 \%$ & $3.4 \%$ & 3.41 & 0.24 \\
\hline Rule-based stopping condition & $27.6 \%$ & $55.2 \%$ & $17.2 \%$ & $0 \%$ & 3.10 & 0.22 \\
\hline Automated animation & $34.4 \%$ & $41.4 \%$ & $20.7 \%$ & $3.4 \%$ & 3.07 & 0.27 \\
\hline Background execution & $41.4 \%$ & $20.7 \%$ & $37.9 \%$ & $0 \%$ & 3.03 & 0.30 \\
\hline Vary animation speed & $27.4 \%$ & $41.4 \%$ & $24.1 \%$ & $6.9 \%$ & 2.90 & 0.31 \\
\hline Parallel execution & $31.0 \%$ & $24.1 \%$ & $37.9 \%$ & $6.9 \%$ & 2.79 & 0.35 \\
\hline
\end{tabular}

Table 8. Importance of model execution features.

The ability to manually interrupt execution, view partial results, make changes to simulation data, and resume model execution is very important (Table 8) to the survey respondents. The ability to execute simulation experiments in the background or in parallel, rulebased stopping conditions are of less importance. Even though animation has recently received much importance in the simulation community, participants only give it a moderate response.

\section{Category: Output Analysis}

\begin{tabular}{|l|r|r|r|r|r|l|}
\hline \multicolumn{1}{|c|}{ Feature } & \multicolumn{1}{c|}{ VI } & \multicolumn{1}{c|}{ I } & LI & NI & Average & CV \\
\hline Hypothesis testing & $62.1 \%$ & $27.6 \%$ & $10.3 \%$ & $0 \%$ & 3.52 & 0.20 \\
\hline Output interpretation & $62.1 \%$ & $27.6 \%$ & $10.3 \%$ & $0 \%$ & 3.52 & 0.20 \\
\hline Confidence intervals & $69.0 \%$ & $6.9 \%$ & $20.7 \%$ & $3.4 \%$ & 3.41 & 0.28 \\
\hline Auto correlation analysis & $55.2 \%$ & $17.2 \%$ & $20.7 \%$ & $6.9 \%$ & 3.21 & 0.32 \\
\hline Experimental designs & $41.4 \%$ & $37.9 \%$ & $13.8 \%$ & $6.9 \%$ & 3.14 & 0.29 \\
\hline Optimization & $25.0 \%$ & $39.3 \%$ & $28.6 \%$ & $7.1 \%$ & 2.82 & 0.32 \\
\hline Regression analysis & $6.9 \%$ & $55.2 \%$ & $27.6 \%$ & $10.3 \%$ & 2.59 & 0.30 \\
\hline Time series analysis & $6.9 \%$ & $48.3 \%$ & $31.0 \%$ & $13.8 \%$ & 2.48 & 0.33 \\
\hline Spectral analysis & $7.1 \%$ & $25.0 \%$ & $50 \%$ & $17.9 \%$ & 2.21 & 0.38 \\
\hline
\end{tabular}

Table 9. Importance of output analysis features.

Several key output analysis features have high ratings (Table 9). Respondents indicate a high preference for the following standard statistical inference procedures: confidence interval 
building; hypothesis testing; experimental design, and auto-correlation analysis. Another highly rated feature is output interpretation. Such a tool is an automated output interpreter which assists a user in analyzing the output data. It can help identify bottlenecks and offer hypotheses as to their cause.

\section{Category: Documentation}

\begin{tabular}{|l|r|r|r|r|r|l|}
\hline \multicolumn{1}{|c|}{ Feature } & \multicolumn{1}{c|}{ VI } & \multicolumn{1}{c|}{ I } & LI & \multicolumn{1}{c|}{ NI } & Average & CV \\
\hline Troubleshooting & $72.4 \%$ & $24.1 \%$ & $3.4 \%$ & $0 \%$ & 3.66 & 0.18 \\
\hline Index & $57.1 \%$ & $35.7 \%$ & $7.1 \%$ & $0 \%$ & 3.50 & 0.18 \\
\hline Programmers guide & $51.7 \%$ & $37.9 \%$ & $6.9 \%$ & $3.4 \%$ & 3.38 & 0.23 \\
\hline Quick start & $48.3 \%$ & $37.9 \%$ & $13.8 \%$ & $0 \%$ & 3.35 & 0.22 \\
\hline Demonstration models & $44.8 \%$ & $41.4 \%$ & $13.8 \%$ & $0 \%$ & 3.31 & 0.22 \\
\hline Statistical background & $44.8 \%$ & $41.4 \%$ & $10.3 \%$ & $3.4 \%$ & 3.28 & 0.24 \\
\hline Keyboard reference card & $51.7 \%$ & $27.6 \%$ & $17.2 \%$ & $3.4 \%$ & 3.28 & 0.27 \\
\hline Tutorial & $31.0 \%$ & $62.1 \%$ & $6.9 \%$ & $0 \%$ & 3.24 & 0.18 \\
\hline Introduction to simulation & $31.0 \%$ & $51.7 \%$ & $17.2 \%$ & $0 \%$ & 3.14 & 0.22 \\
\hline
\end{tabular}

Table 10. Importance of user documentation features.

From the consistent responses for documentation features (Table 10), we are confident in saying that a user expects thorough and well-written documentation to accompany any simulation tool. A troubleshooting section in the documentation that describes errors and offers remedies is one of the higher rated features of the survey. Other important documentation features include: a quick start section to provide a brief introduction to the environment; a tutorial section, and an index of important topics along with the pages on which they are discussed. Additional sections requested are: an introduction on how to perform a simulation study; a review of key statistical concepts; a discussion of modeling examples; a programmer or technical reference manual on the simulation environment, and a keyboard reference card(s) on the program structure and commands. 


\section{Category: Simulation Project Data}

\begin{tabular}{|l|r|r|r|r|r|c|}
\hline \multicolumn{1}{|c|}{ Feature } & VI & I & LI & NI & Average & CV \\
\hline Input data & $69.0 \%$ & $31.0 \%$ & $0 \%$ & $0 \%$ & 3.69 & 0.11 \\
\hline Simulation models & $62.1 \%$ & $37.9 \%$ & $0 \%$ & $0 \%$ & 3.62 & 0.14 \\
\hline Simulation results & $58.6 \%$ & $41.4 \%$ & $0 \%$ & $0 \%$ & 3.59 & 0.14 \\
\hline Experimental conditions & $55.2 \%$ & $37.9 \%$ & $6.9 \%$ & $0 \%$ & 3.48 & 0.18 \\
\hline Project reports & $17.2 \%$ & $51.7 \%$ & $31.0 \%$ & $0 \%$ & 2.86 & 0.24 \\
\hline
\end{tabular}

Table 11. Importance of features for saving simulation project information.

The majority of respondents indicate a great need for database storage of project work (Table 11). Data to store include: input data; simulation run-time experimental conditions; simulation models; simulation sub-models, and simulation results. Of lesser importance is the need to store project reports.

\section{Category: Methods of User Interface}

\begin{tabular}{|l|r|r|r|r|r|c|}
\hline \multicolumn{1}{|c|}{ Feature } & \multicolumn{1}{c|}{ VI } & I & LI & NI & Average & CV \\
\hline Mouse & $72.4 \%$ & $20.7 \%$ & $6.9 \%$ & $0 \%$ & 3.66 & 0.17 \\
\hline Keyboard & $69.0 \%$ & $24.1 \%$ & $3.4 \%$ & $3.4 \%$ & 3.59 & 0.20 \\
\hline Trackball & $6.9 \%$ & $20.7 \%$ & $51.7 \%$ & $20.7 \%$ & 2.14 & 0.39 \\
\hline Scanner & $3.4 \%$ & $20.7 \%$ & $55.2 \%$ & $20.7 \%$ & 2.07 & 0.36 \\
\hline Voice recognition & $6.9 \%$ & $10.3 \%$ & $58.6 \%$ & $24.1 \%$ & 2.00 & 0.40 \\
\hline Touch screen & $6.9 \%$ & $24.1 \%$ & $31.0 \%$ & $37.9 \%$ & 2.00 & 0.48 \\
\hline
\end{tabular}

Table 12. Importance of user interface features.

A keyboard and mouse are the most important methods of user interface (Table 12). Note that the use of a mouse has a higher rating than that of a keyboard. Not surprisingly, other methods of inputting data faired quite poorly. 


\subsection{Conclusion}

One of the significant disadvantages of discrete-event simulation is that the quality of the analysis depends on the quality of the model. This problem is compounded with the fact that many of the people building simulation models have limited practical experience. Sadowski [23] remarks that "although mistakes will be made, hopefully the simulation tool will become a valuable addition to the analyst's set of capabilities." Simulation tools therefore offer an advanced solution to the problem of inexperienced model building. However, with this advancement comes the problem of identifying and defining the important simulation features that should be present in such tools. To solve this problem, we present the results of a survey that attempts to ascertain important features for industrial simulation environments. The results of this survey are interesting and suggest to Simulation readers potential areas for environment enhancement and future development.

\begin{tabular}{|l|c|}
\hline \multicolumn{1}{|c|}{ Feature } & Rank \\
\hline A consistent and user friendly interface & 1 \\
\hline Database storage capabilities for input data & 2 \\
\hline An interactive debugger for error checking and code tracing & 3 \\
\hline Interaction via a mouse & 4 \\
\hline A troubleshooting section in the documentation & 5 \\
\hline Storage capabilities for simulation models & 6 \\
\hline Storage capabilities for simulation results & 7 \\
\hline Ability to input data and commands by keyboard & 8 \\
\hline A library of reusable modules of simulation code & 9 \\
\hline $\begin{array}{l}\text { Ability to graphically display input, output, and run-time } \\
\text { statistics }\end{array}$ & 10 \\
\hline
\end{tabular}

Table 13. Top ten rated simulation environment features.

The top ten simulation features identified by the survey participants are listed in Table 13. Even though graphical display of data is important, the most strongly request feature is a consistent and friendly user interface. For assistance when problems occur, practitioners desire a good troubleshooting section in the documentation. The results also indicate that practitioners would like more ability to store, retrieve and process their model scenarios both during initial model creation and throughout subsequent model reuse. This desire for database storage 
capability of project data and reuse of simulation code are important areas for exploration and development.

\section{Acknowledgments}

We wish to thank the National Institute of Standards and Technology, the Institute of Manufacturing and Automated Research (IMAR), and the Consortium for Advanced Manufacturing International (CAM-I) for their support and participation in this study. In addition, we wish to acknowledge the contribution of the graduate students associated with the SSL. Without the project efforts of these individuals, the development of the questionnaire and this paper would not be possible.

\section{References}

[1] Pegden, C. D. , Shannon, R. E., and Sadowski, R. P. (1990) Introduction to Simulation Using SIMAN. McGraw Hill, New York, New York.

[2] ProModel PC User's Manual (1989) Production Modeling Corporation, Orem, Utah.

[3] Ford, D. R. and Schroer, B. J. (1987) An Expert Manufacturing Simulation System. Simulation, Vol. 48, No. 5, pp. 193-200.

[4] Cox, S. W. (1991) GPSS WORLD: A Brief Preview. In Proceedings of the 1991 Winter Simulation Conference, Phoenix, AZ, December 1991, pp. 59-61.

[5] Mellichamp, J. M. and Park, Y. H. (1989) A Statistical Expert System for Simulation Analysis. Simulation, Vol. 52, No. 4, pp. 134-139.

[6] Vincent, S. G. and Law, A. M. (1991) UniFit II: total support for simulation input modeling. In Proceedings of the 1991 Winter Simulation Conference, Phoenix, AZ, pp. 126-142.

[7] Haddock, J. (1987) An Expert System Framework Based On a Simulation Generator. Simulation, Vol. 48, No. 2, 45-53.

[8] Balmer, D. W. and Paul, R. J. (1986) CASM - The Right Environment for Simulation. Journal of Operations Research Society, Vol. 37, No. 5, pp. 443-452.

[9] Schruben, L.W. (1992) SIGMA: Graphical Simulation Modeling. The Scientific Press, San Francisco, California. 
[10] Mackulak, G.T. and Cochran, J.K. (1989) Mascot: A Prolog-Based Simulation Modeling and Training Environment. In Modeling and Simulation Methodology: Knowledge Systems Paradigms (Elzas, Oren, and Zeigler, editors), North Holland, Elsevier Science Publishers, pp. 145-160.

[11] Mackulak, G.T. and Cochran, J.K. (1990) Generic/Specific Modeling: An Improvement to CIM Simulation Techniques. In Optimization of Manufacturing Systems Design (D. Shunk, editor), North-Holland, pp. 237-260.

[12] Mackulak, G.T. and Cochran, J.K. (1987) MASCOT: A Prolog-Based Simulation Modeling and Training Environment. In Proceedings of the International Symposium on Modeling and Simulation Methodology - Intelligent Environments and Goal-Directed Models, Tucson, AZ, pp. 18-21.

[13] Mackulak, G.T. and Cochran, J.K. (1990) The Generic-Specific Modeling Approach: An Application of Artificial Intelligence to Simulation. In Proceedings of the IIE Integrated Systems Conference, San Antonio, TX, pp. 82-87.

[14] Ozdemirel, N.E., Mackulak, G.T., and Cochran, J.K. (1993) A Group Technology Classification and Coding Scheme for Discrete Manufacturing Simulation Models. International Journal of Production Research , Vol. 33, No. 3, pp. 579-601.

[15] Manathkar, U.G., Mackulak, G.T., and Cochran, J.K. (1992) A New Approach to Simulation Studies Based on Generic Abstracts of the System. In Proceedings of the International Simulation Technology Conference, Houston, TX, pp. 166-171.

[16] Fegan, J. M., Lane, G. M. and Nolan, P. J. (1991) Introduction to Simulation Using Intelligent Simulation Interface (ISI). In Proceedings of the 1991 Winter Simulation Conference, Phoenix AZ, pp. 143-147.

[17] Banks, J., Aviles, E., McLaughlin, J.R., and Yuan, Robert C. (1991) The Simulator: New Member of the Simulation Family. Interfaces, Vol. 21, No. 2, pp. 76-86.

[18] Reddy, Y. V., Fox, M. S., Husain, N., and McRoberts, M. (1986) The Knowledge Based Simulation System. IEEE Software Vol. 3, No. 2, pp. 26-37.

[19] Cochran, J. K., Mackulak, G. T., Castillo, D., and Du, E. (1987) Configuring Available Software into an AI/ES environment for Automated Manufacturing Simulation Design on the PC. In Proceedings of the Conference on Simulation of Computer Integrated Manufacturing Systems and Robotics, San Diego, CA, pp. 1-7.

[20] Law, A. M. and McComas, M. G. (1992) How to Select Simulation Software for Manufacturing Applications. Industrial Engineering Vol. 24, No. 7, 29-35.

[21] Banks, J. (1991) Selecting Simulation Software. In Proceedings of the 1991 Winter Simulation Conference, Phoenix, AZ, pp. 15-20. 
[22] Cochran, J. K. , Manathkar, U. G., and Mackulak, G. T. (1993) Multi-Level Software Beta Testing: An IntelliSIM Case Study. In the Proceedings of the Conference on Simulation in Business Management and MIS, San Diego, CA, pp. 103-108.

[23] Sadowski, R. (1989) The Simulation Process: Avoiding the Problems and Pitfalls. In Proceedings of the 1989 Winter Simulation Conference, Washington D.C., pp. 72-79. 